\title{
Retinopathy of Prematurity Stage 4 Subtotal Retinal Detachment
}

National Cancer Institute

\section{Source}

National Cancer Institute. Retinopathy of Prematurity Stage 4 Subtotal Retinal

Detachment. NCI Thesaurus. Code 699050.

An ophthalmoscopic finding that references retinopathy of prematurity characterized by the presence of subtotal retinal detachment. 